\title{
Training of French Nursing Students on Drawing Blood Culture: Results from a Broad Electronic Survey
}

\section{Barbara Alves and Romain Jouffroy*}

Department of Anaesthesia \& Intensive Care Unit, SAMU, Hôpital Universitaire Necker - Enfants Malades, Université Paris Descartes, France

*Corresponding author: Romain Jouffroy, M.D., Department of Anaesthesia \& Intensive Care Unit - SAMU, Assistance Publique - Hôpitaux de Paris, Hôpital Universitaire Necker - Enfants Malades, Université Paris Descartes, 149 rue de Sèvres, 75015 Paris, France, Tel: (+33)-1-44-49-24-72, Fax: (+33)-1-44-49-23-25

\begin{abstract}
Introduction: Early implementation of appropriate treatments reduces mortality of sepsis, but before starting antibiotherapy, drawing blood culture is essential to identify the source of sepsis and to adapt treatment. Suboptimal practices result in blood culture contamination from patient's skin at the venepuncture site. As blood culture is the standard method to diagnose a bacteraemia, appropriate training of nursing students can promote good clinical practice.

This study aims to evaluate the teaching and the training of French nursing students on blood culture execution and related hygiene practices.
\end{abstract}

Methods: The study design was a cross-sectional audit based on an electronic questionnaire sent to the 10,000 French nursing students over a 4 months period.

Results: One thousand and thirty-six nursing students filled out the survey, representing around $10 \%$ of the French nursing students. At nursing school, $30 \%$ of the nursing students declared to have received theoretical and practical training on blood culture. During their internship, 45\% declared no training on it. Among blood culture execution recommendations, peripheral stick and first aerobic were well known among $88 \%$ and $83 \%$ of the nursing students, respectively. Similarly, the practice of washing hands and cleaning the venepuncture site prior to blood culture execution were known among $96 \%$ and $94 \%$ of nursing students. In contrast, the practice of wearing gloves $(80 \%)$ and facial mask $(15 \%)$ is relatively lower.

Conclusion: There are discrepancies between the knowledge of nursing students and good practice recommendations for blood culture execution and related hygiene practices. Strengthening the teaching practices will likely improve students' knowledge base, reduce blood culture contamination and improve quality of care.

\section{Keywords}

Evaluation, Good practice, Nursing students, Training

\section{Introduction}

Sepsis a major public health problem, with an estimated incidence of 300 per 100,000 inhabitants [1,2]. Sepsis is involved in one-third to one-half of all in-hospital deaths [3] with a mortality rate reaching 30\% $[1,2,4,5]$. The outcome of septic patients relies on the early identification and rapid implementation of appropriate treatments, especially hemodynamic optimization and antibiotics administration, named bundle of cares $[3,6]$ whose efficacy to reduce mortality is proven [6-12]. Most of the time, sepsis results from a bacteraemia [13].

Blood cultures are the standard method for the diagnosis of bacteraemia. A blood culture consists of taking a predefined volume of blood in order to identify the germ(s) responsible of the bacteraemia. The "sepsis-3" conference underlined that the quality of blood culture is at the utmost importance to first allow the identification of the origin of sepsis and second to adapt antibiotic treatment based on lab results [14]. To reach this goal, recommendations for blood culture drawing practices have been performed but vary between countries [15-18].

However, bad practices are involved in blood culture contamination with an approximate rate of $3 \%$ in the

Citation: Alves B, Jouffroy R (2018) Training of French Nursing Students on Drawing Blood Culture: Results from a Broad Electronic Survey. Int Arch Nurs Health Care 4:104. doi.org/10.23937/24695823/15100104

Accepted: November 06, 2018: Published: November 08, 2018

Copyright: (C) 2018 Alves B, et al. This is an open-access article distributed under the terms of the Creative Commons Attribution License, which permits unrestricted use, distribution, and reproduction in any medium, provided the original author and source are credited. 
US [19]. Blood culture contamination results in unnecessary and insensible antibiotic use, increased length of hospital stay and increased healthcare costs $[20,21]$. Patient's skin at the venepuncture site is often the source of blood culture contamination [22]. In order to reduce blood culture contamination rates, the efficacy of good practice recommendations, pre-packaged antisepsis kits, dedicated phlebotomy teams as frequent and easily accessible training have been observed $[23,24]$.

However, teaching, training and practices of blood culture drawing varies among countries [15-18]. For example, in France, blood cultures are mainly taken by nurses. Therefore, in order to promote good clinical practices and reduce consequences of false positive blood culture, enhancing appropriate initial teaching and training of nursing students appears to be essential.

The aim of this study is to evaluate the teaching and the training received by French nursing students at school and hospital on blood culture execution and related hygiene practices.

\section{Methods and Statistical Analysis}

\section{French specificities}

French blood culture guidelines, lastly updated in 2015 [16], underline that in case of sepsis, blood culture, aerobic and anaerobic, should be performed immediately, and before any antibiotic administration [25]. The French and international guidelines recommend sampling a unique peripheral sample, first aerobic bottle and second anaerobic bottle, in order to optimize the sensitivity for the detection of microorganism $[15,26]$. In France, a nurse can perform blood culture without any supervision in accordance with the ward protocols.

Two theoretical lessons concerning blood culture execution are dispensed: 1 during the first year and 1 during the second year [27]. The practical teaching is dispensed during the internship during one of the 3 years of the initial training for French nursing students.

\section{Study design}

A cross-sectional study aiming to evaluate the teaching and the training received by French nursing students on blood culture execution and related hygiene practices based on a survey was performed. The survey was based on a questionnaire (Annex 1 ) sent out to all French nursing schools between October 2017 and January 2018.

The questionnaire was established by a nurse after discussion between two nurses and two staff physicians leading to a consensus on its contents. The questionnaire encompassed 22 short answer questions and multiple-choice questions exploring the theoretical and practical aspects of teaching and training received by nursing students on hygiene practices concerning blood culture practice. The external validity was evaluated with 10 nurse students fulfilling the questionnaire to ensure understanding and clarity of issues.

\section{Ethical considerations}

Student participation was voluntary. In the electronic-mail it was specified that "the participation is totally voluntary, and the participants can withdraw from the study anytime without giving any reason". According to the French law, the study was exempted by Human Subjects Committee review considering that the study as a voluntary audit.

\section{Data collection}

All responses were collected electronically via Google Form ${ }^{\circ}$.

\section{Analysis}

Quantitative data are expressed as mean \pm standard deviation (SD). Qualitative variables are expressed as frequency with percentage.

\section{Results}

One thousand and thirty-six nursing students filled out the survey representing a response rate of $10 \%$ of the 10,000 French nursing students. Of these, $90 \%$ were female. The mean age was $24 \pm 6$ years. Among the responders, $48 \%$ were third year, $38 \%$ second year and $14 \%$ first year nursing students.

These students did an internship in medicine, surgery or obstetric ward (81\%), geriatric ward (76\%), psychiatry ward $(70 \%)$, intensive care unit $(19 \%)$ and in the emergency department (10\%).

At nursing school, only $57 \%$ of the nursing students declared to have received theoretical training on blood culture execution. During their internship, $87 \%$ received practical training only and $30 \%$ theoretical and practical training. Of them, $95 \%$ thought that improvement on training could allow better care: $66 \%$ prefer a theoretical and practical training at nursing school whereas $42 \%$ prefer that the training should be performed during the internship.

Moreover, 28\% declared to have no knowledge of recommendations on blood culture handling and $12 \%$ declared a lack of blood culture protocol during the internship.

Unique sample is considered as the gold standard by $27 \%$ of nurse students.

Main results are summarized in Table 1.

\section{Discussion}

In this study, we observed discrepancies between good practice recommendations and declared knowledges, theoretical and practical, for blood culture practices among nursing students. Thus, opportunities exist to improve blood culture related practices for nursing students to reduce blood culture contamination, im- 
Table 1: A summary of survey results.

n Percentage

\section{Training}

\section{At nursing school}

Theoretical training

Practical training

Theoretical and practical training

During internship

Theoretical training during

Practical training during

No training

.

$+2$

\begin{tabular}{|c|c|c|}
\hline \multicolumn{3}{|l|}{ Practice } \\
\hline Coaching during first BC & 487 & $47 \%$ \\
\hline Coaching during first $5 \mathrm{BC}$ & 93 & $9 \%$ \\
\hline Coaching during all BC & 238 & $23 \%$ \\
\hline No coaching during $B C$ & 124 & $12 \%$ \\
\hline Drawn > 5 BC & 290 & $28 \%$ \\
\hline Drawn $2<\mathrm{BC}<5$ & 249 & $24 \%$ \\
\hline Drawn $1<\mathrm{BC}<2$ & 269 & $26 \%$ \\
\hline No BC drawn & 228 & $22 \%$ \\
\hline $\mathrm{BC}$ from peripheral stick & 912 & $88 \%$ \\
\hline $\mathrm{BC}$ from arterial line & 73 & $7 \%$ \\
\hline $\mathrm{BC}$ from central venous device & 321 & $31 \%$ \\
\hline Cleaning the BC bottle top & 736 & $71 \%$ \\
\hline > $8 \mathrm{ml}$ of blood sample & 207 & $20 \%$ \\
\hline 6 to $8 \mathrm{ml}$ of blood sample & 425 & $41 \%$ \\
\hline $5 \mathrm{ml}$ of blood sample & 332 & $32 \%$ \\
\hline Aerobic BC first & 860 & $83 \%$ \\
\hline Anaerobic BC first & 176 & $17 \%$ \\
\hline \multicolumn{3}{|l|}{ Hygiene practices } \\
\hline Washing hands prior to $B C$ & 995 & $96 \%$ \\
\hline Cleaning venepuncture site prior to $B C$ & 974 & $94 \%$ \\
\hline Wearing gloves & 829 & $80 \%$ \\
\hline Wearing a facial mask & 155 & $15 \%$ \\
\hline
\end{tabular}

$\mathrm{n}$ : Number of answers; NS: Nursing school; IS: Internship; BC: Blood culture.

prove quality of care and reduce hospital length of stay and related health care costs.

In France, nurses are most of the time female [28]. The important rate of female responders in this study is consistent with the demography of French nursing students [29].

Despite international and national good practice recommendations for blood culture execution $[15,17,18,30]$, we observed major differences in what the students knew regarding blood culture practices. The recommendations about "peripheral stick" and "first aerobic blood culture execution" are relatively well known in contrast to other recommendations: Single-sampling, cleaning the blood culture bottle tops, blood volume sampled and wearing a facial mask. Single-sampling is not considered as the gold by most of the student despite evidence in favour this last one. Single-sampling reduces the incidence of contamination [31-33] and improve the diagnosis performance of blood culture [32,34]. Adequate volume sampling is the most important parameter for the detection of bloodstream infection, thus a minimal of $8-10 \mathrm{~mL}$ of blood is required [26]. The contamination rate is lower when samples are drawn by peripheral venipuncture $[26,35]$. To avoid contamination, cleaning the top of blood culture bottle is therefore recommended $[15,26]$. The WHO guidelines on drawing blood contain the best practices for health worker particularly hygiene practices [36].

The discrepancies observed between recommendations and the declaration of nursing students in this study may explain the persistent contamination rate of $3 \%$ observed in France as in other countries [19,37]. The herein results are consistent with other studies [35,38].

We plan to use the results of this survey to underline the necessity to reinforce the teaching of good healthcare practices during in-class as well as in-hospital training of nursing students in France. It is essential for nursing students to have a sound knowledge base of good healthcare practices which is the first step in reducing blood culture contamination. It is hoped that this will eventually lead to an improvement in infectious agent identification and a reduction of inappropriate antibiotics administration.

\section{Limits}

Some limitations in our study deserve consideration. First, it is a declarative survey about practices and not an observational study of daily practices. Second, part of the results observed here may result from poor teaching practices at hospitals for the nursing staff. Third, the sample is not equally dispatched between the 3 years. There is a low percentage of first-year nursing students, that could artificially enhanced results. Fourth, since the recommendations were updated in 2015, it is possible that not all nursing schools updated their program which could have negatively impacted the results. Fifth, our results are not directly transposable to other countries because teaching and training programs are not the same than in France.

However, strengthening the teaching and the training of nurse students is an easy way to improve knowledge and skills in order to enhance blood culture practice and quality of care.

\section{Conclusion}

The knowledge base of nursing students does not correspond with good practice recommendations for blood culture execution. Strengthening the teaching practices at nursing schools and the training during the internship would probably help to improve knowledge base and reduce blood culture contamination. At the end, this may also contribute to improve quality of care and reduce health care related costs. 


\section{Acknowledgments}

Authors appreciate the English revision made by Ms Pakeezah Saadat health research methodology candidate, Mc Master University Hamilton, Ontario Canada.

\section{References}

1. Jawad I, Luksic I, Rafnsson SB (2012) Assessing available information on the burden of sepsis: Global estimates of incidence, prevalence and mortality. J Glob Health 2: 010404.

2. Gaieski DF, Edwards JM, Kallan MJ, Carr BG (2013) Benchmarking the incidence and mortality of severe sepsis in the United States. Crit Care Med 41: 1167-1174.

3. Liu V, Escobar GJ, Greene JD, Soule J, Whippy A, et al. (2014) Hospital deaths in patients with sepsis from 2 independent cohorts. JAMA 312: 90-92.

4. ProCESS Investigators, Yealy DM, Kellum JA, Huang DT, Barnato AE, et al. (2014) A randomized trial of protocol-based care for early septic shock. N Engl J Med 370: 1683-1693.

5. Annane D, Aegerter $P$, Jars-Guincestre MC, Guidet B, Network CUB-Réa (2003) Current epidemiology of septic shock: The CUB-Rea Network. Am J Respir Crit Care Med 168: $165-172$.

6. Prasad PA, Shea ER, Shiboski S, Sullivan MC, Gonzales $\mathrm{R}$, et al. (2017) Relationship between a sepsis intervention bundle and In-Hospital mortality among hospitalized patients: A Retrospective Analysis of Real-World Data. Anesth Analg 125: 507-513.

7. Damiani E, Donati A, Serafini G, Rinaldi L, Adrario E, et al. (2015) Effect of performance improvement programs on compliance with sepsis bundles and mortality: A systematic review and meta-analysis of observational studies. PLoS One 10: e0125827.

8. Kalil AC, Kellum JA (2017) Is early goal-directed therapy harmful to patients with sepsis and high disease severity? Crit Care Med 45: 1265-1267.

9. Kalil AC (2017) Antibiotic combination therapy for patients with Gram-Negative septic shock. Crit Care Med 45: 19331936.

10. Leisman DE, Doerfler ME, Ward MF, Masick KD, Wie BJ, et al. (2017) Survival benefit and cost savings from compliance with a simplified 3-hour sepsis bundle in a series of Prospective, Multisite, Observational Cohorts. Crit Care Med 45: 395-406.

11. Rivers E, Nguyen B, Havstad S, Ressler J, Muzzin A, et al. (2001) Early goal-directed therapy in the treatment of severe sepsis and septic shock. N Engl J Med 345: 1368-1377.

12. Rhodes A, Phillips G, Beale R, Cecconi M, Chiche JD, et al. (2015) The Surviving Sepsis Campaign bundles and outcome: Results from the International Multicentre Prevalence Study on Sepsis (the IMPreSS study). Intensive Care Med 41: 1620-1628.

13. Bone RC, Balk RA, Cerra FB, Dellinger RP, Fein AM, et al. (1992) Definitions for sepsis and organ failure and guidelines for the use of innovative therapies in sepsis. The ACCP/SCCM Consensus Conference Committee. American College of Chest Physicians/Society of Critical Care Medicine. Chest 101: 1644-1655.

14. Singer M, Deutschman CS, Seymour CW, Shankar-Hari M, Annane D, et al. (2016) The third international consensus definitions for sepsis and septic shock (Sepsis-3). JAMA 315: 801-810.
15. Reimer LG, Wilson ML, Weinstein MP (1997) Update on detection of bacteremia and fungemia. Clin Microbiol Rev 10: 444-465.

16. REMIC (2015) REMIC Référentiel en microbiologie médicale. ( $5^{\text {th }}$ edn), SFM, SFP, SFMM.

17. Washington JA 2nd, Ilstrup DM (1986) Blood cultures: Issues and controversies. Rev Infect Dis 8: 792-802.

18. Weinstein MP (1996) Current blood culture methods and systems: Clinical concepts, technology, and interpretation of results. Clin Infect Dis 23: 40-46.

19. Hall KK, Lyman JA (2006) Updated review of blood culture contamination. Clin Microbiol Rev 19: 788-802.

20. Souvenir D, Anderson DE Jr, Palpant S, Mroch H, Askin S, et al. (1998) Blood cultures positive for coagulase-negative staphylococci: Antisepsis, pseudobacteremia, and therapy of patients. J Clin Microbiol 36: 1923-1926.

21. van der Heijden YF, Miller G, Wright PW, Shepherd BE, Daniels TL, et al. (2011) Clinical impact of blood cultures contaminated with coagulase-negative staphylococci at an academic medical center. Infect Control Hosp Epidemiol 32: 623-625.

22. Story-Roller E, Weinstein MP (2016) Chlorhexidine versus tincture of iodine for reduction of blood culture contamination rates: A prospective randomized crossover study. J Clin Microbiol 54: 3007-3009.

23. Nair A, Elliott SP, Al Mohajer M (2017) Knowledge, attitude, and practice of blood culture contamination: A multicenter study. Am J Infect Control 45: 547-548.

24. Weinbaum FI, Lavie S, Danek M, Sixsmith D, Heinrich GF, et al. (1997) Doing it right the first time: Quality improvement and the contaminant blood culture. $\mathrm{J}$ Clin Microbiol 35: 563-565.

25. Pottecher T, Calvat S, Dupont H, Durand-Gasselin J, Gerbeaux P, et al. (2006) Haemodynamic management of severe sepsis: Recommendations of the French Intensive Care Societies (SFAR/SRLF) Consensus Conference, 13 October 2005, Paris, France. Crit Care 10: 311.

26. Lamy B, Dargere S, Arendrup MC, Parienti JJ, Tattevin P (2016) How to optimize the use of blood cultures for the diagnosis of bloodstream infections? A State-of-the Art. Front Microbiol 7: 697.

27. Legifrance (2009) Arrêté du 31 juillet 2009 relatif au diplôme d'Etat d'infirmier.

28. M Barlet MC (2011) La profession d'infirmière: Situation démographique et trajectoires professionnelles. Direction de la recherche, des études, de l'évaluation et des statistiques (DREES).

29. B C-S (2016) Profil des infirmiers en formation en 2014. Direction de la recherche, des etudes, de l'evaluation et des statistiques.

30. SF2H (2016) Recommandations: Antisepsie de la peau saine avant un geste invasif chez l'adulte.

31. Arendrup M, Jensen IP, Justesen T (1996) Diagnosing bacteremia at a Danish hospital using one early large blood volume for culture. Scand J Infect Dis 28: 609-614.

32. Dargere S, Parienti JJ, Roupie E, Gancel PE, Wiel E, et al. (2014) Unique blood culture for diagnosis of bloodstream infections in emergency departments: A prospective multicentre study. Clin Microbiol Infect 20: 920-927.

33. Li J, Plorde JJ, Carlson LG (1994) Effects of volume and periodicity on blood cultures. J Clin Microbiol 32: 2829-2831. 
34. Lamy B, Roy P, Carret G, Flandrois JP, Delignette-Muller ML (2002) What is the relevance of obtaining multiple blood samples for culture? A comprehensive model to optimize the strategy for diagnosing bacteremia. Clin Infect Dis 35: 842-850.

35. Snyder SR, Favoretto AM, Baetz RA, Derzon JH, Madison BM, et al. (2012) Effectiveness of practices to reduce blood culture contamination: A Laboratory Medicine Best Practices systematic review and meta-analysis. Clin Biochem 45: 999-1011.

Annex 1: Questionnaire used for the survey.

1. Sex:

$$
\begin{aligned}
& \square \text { Man } \\
& \square \text { Woman }
\end{aligned}
$$

2. How old are you:

3. Your training year: *

$$
\begin{aligned}
& \square 1^{\text {st }} \text { year } \\
& \square 2^{\text {nd }} \text { year } \\
& \square 3^{\text {rd }} \text { year }
\end{aligned}
$$

4. What field(s) of internship did you complete (adult and paediatric)?

$\square$ MSO (medicine, surgery, obstetrics)
$\square$ Classical ward
$\square$ Long-term care
$\square$ Psychiatry
$\square$ Intensive care unit
$\square$ Emergency department

5. At nursing school, did you have a theoretical course on performing blood cultures?

$$
\begin{aligned}
& \square \text { Yes } \\
& \square \text { No }
\end{aligned}
$$

6. At nursing school, did you have a hands-on course on performing blood cultures?

$$
\begin{aligned}
& \square \text { Yes } \\
& \square \text { No }
\end{aligned}
$$

7. How did graduate nurse train you during internship?

$$
\begin{aligned}
& \square \text { Only in practice } \\
& \square \text { Only on theory (service protocol, knowledge } \\
& \text { control) } \\
& \square \text { Theoretical and practical } \\
& \square \text { No training received }
\end{aligned}
$$

8. Have you read or read any protocols concerning the collection of blood cultures (protocol of service, recommendations ...)?

\section{$\square$ Yes \\ $\square$ No}

$\square$ I was not aware of the existence of protocols, recommendations
36. World Health Organization (2010) WHO guidelines on drawing blood: Best practices in phlebotomy.

37. Leyssene D, Gardes S, Vilquin P, Flandrois JP, Carret G, et al. (2011) Species-driven interpretation guidelines in case of a single-sampling strategy for blood culture. Eur $\mathrm{J}$ Clin Microbiol Infect Dis 30: 1537-1541.

38. Stohl S, Benenson S, Sviri S, Avidan A, Block C, et al. (2011) Blood cultures at central line insertion in the intensive care unit: Comparison with peripheral venipuncture. J Clin Microbiol 49: 2398-2403.

$\square$ There was no protocol for blood cultures in the service

9. How much did you have to take blood culture drawing on an internship?

$\square 1$ or 2 times
$\square$ Between 2 and 5 times
$\square$ More than 5 times
$\square$ None

10. Were you supervised during the $B C$ drawing by a graduate nurse?

$\square$ The first time only
$\square$ The first 5 times
$\square$ Each time
$\square$ Never

11. In what context did you take blood cultures during internship?
$\square$ Suspicion of bacteraemia
$\square$ Suspicion of endocarditis
Febrile aplasia/immunodepression
$\square$ Systematic balance sheet
$\square$ I do not remember

12. When collecting a pair of blood cultures, at which site do you sample?

\section{Peripheral preferentially}

On an intravascular device

On an intravascular device because the patient is difficult to sting

$\square$ In arterial

13. When there is a suspicion of bacteraemia, how many pairs of blood cultures do you take?
3 pairs in one puncture
$\square 1$ pair only in one puncture
$\square 3$ pairs spread over 24 hours in several punc- tures

More than 3 pairs over 24 hours

14. Have you ever been faced to a differential blood culture sample? 
$\square$ Yes

$\square$ No

I do not know what this term means

15. In your opinion, in the case of differential blood cultures, are there any special precautions?

$\square$ No, no

$\square$ All vials had to be filled with the same volume of blood

$\square$ Annotate vials per sample site is important

$\square$ The sampling time at all puncture sites must be less than 10 minutes

16. For a $\mathrm{BC}$, do you think the order of sample collection is important (aerobic/anaerobic)?

$\square$ Yes, aerobic before anaerobic

$\square$ Yes, anaerobic before aerobic

$\square$ The order does not matter

17. How much blood did you take?

$\square$ Few drops of blood, the volume does not matter

$\square$ About $5 \mathrm{ml}$

Between 6 and $8 \mathrm{ml}$

More than $8 \mathrm{ml}$

18. What, in your opinion, are the aseptic rules to follow when performing blood cultures?

$\square$ Washing hands with a hydroalcoholic solution

Wearing sterile gloves

$\square$ Wearing a surgical mask

$\square$ Cleaning the top of blood culture bottles with antiseptic

\section{$\checkmark$ Wearing non-sterile gloves \\ $\square$ Disinfection of the patient's skin with antisep- tic}

19. When the blood culture is not sent directly to the laboratory, where should they be kept?

\section{$\square$ At room temperature \\ $\square$ In the fridge}

20. Do you think that training on blood culture harvesting at nursing school would be beneficial and would optimize patient care?

$$
\begin{aligned}
& \square \text { Yes } \\
& \square \text { No }
\end{aligned}
$$

21. Regarding the collection of blood cultures, how would you like to be trained to improve your practices?

$$
\begin{aligned}
& \square \text { Theory and practice at nursing school } \\
& \square \text { Nursing school theory and internship practice } \\
& \square \text { Theory and practice in internship by graduate } \\
& \text { nurse } \\
& \square \text { Theoretical training (books, recommenda- } \\
& \text { tions, protocols) and practice in internship } \\
& \square \text { I do not need special training }
\end{aligned}
$$

22. Do you think that the theoretical/practical training on biological samples (beyond blood cultures) is not sufficient?

$$
\begin{aligned}
& \square \text { Yes } \\
& \square \text { No } \\
& \square \text { Without opinion }
\end{aligned}
$$

